Int. J. Electrochem. Sci., 14 (2019) $2893-2905$

International Journal of

ELECTROCHEMICAL

SCIENCE

www.electrochemsci.org

\title{
Photoelectrochemical Degradation of 4-Nitrophenol using CuO- ZnO/exfoliated graphite Nanocomposite Electrode
}

\author{
Onoyivwe Monday Ama ${ }^{1,3, *}$, Khotso Khoele ${ }^{2,3}$, William Wilson Anku ${ }^{1}$, Suprakas Sinha Ray ${ }^{1,3}$ \\ ${ }^{1}$ Department of Applied Chemistry, University of Johannesburg, Doornfontein, 2028 South Africa. \\ ${ }^{2}$ Tshwane University of Technology, Department of Chemical, Metallurgical and Materials \\ Engineering, Pretoria, South-Africa \\ ${ }^{3}$ DST/CSIR National Center for Nano-structured Materials, Council for Scientific and Industrial \\ Research, Pretoria 0001 South Africa. \\ *E-mail: onoyivwe4real@gmail.com
}

doi: $10.20964 / 2019.03 .29$

Received: 25 October 2018 / Accepted: 3 December 2018 / Published: 7 February 2019

There has been a focused attention on the degradation of phenol and its nitro derivatives in industrial wastewater prior to its discharge into the environment due to the carcinogenic potential of these pollutants on biota. Hence, this study focused on the application of photoelectrochemical technique in the degradation of 4-Nitrophenol from simulated wastewater by using synergistic photoactive material $(\mathrm{CuO}-\mathrm{ZnO})$ combined with exfoliated graphite (EG) through co-precipitation method. The experiment was performed using $\mathrm{EG}, \mathrm{CuO}-\mathrm{ZnO}$ and $\mathrm{EG} / \mathrm{CuO}-\mathrm{ZnO}$ electrodes. Characterization techniques engaged to assess the morphology, crystallinity, surface area and chemical properties of the composites include SEM, TEM, XRD, UV-Vis and FTIR spectroscopies. The XRD analysis revealed that the CuO and $\mathrm{ZnO}$ exist in cubic and hexagonal phases respectively. SEM analysis showed a good dispersion of the $\mathrm{CuO}-\mathrm{ZnO}$ onto the EG. The modification of the $\mathrm{CuO}-\mathrm{ZnO}$ with $\mathrm{EG}$ endowed the composite with a larger surface area and strong light absorption in the visible light region. All the fabricated electrodes degraded the dye. However, the $\mathrm{EG} / \mathrm{CuO}-\mathrm{ZnO}$ demonstrated the highest degradation efficiency. The EG showed the least efficiency. The EG/CuO-ZnO was also used in the degradation of the dye on the basis of three techniques namely photolysis, electrochemical, and photoelectrochemical methods. The photoelectrochemical method showed a faster degradation when compared with photolysis and electrochemical oxidation. The synergistic effects of $\mathrm{CuO}, \mathrm{ZnO}$ and $\mathrm{EG}$ promoted the efficiency of the $\mathrm{EG} / \mathrm{CuO}-\mathrm{ZnO}$ against the degradation of the dye.

Keywords: Exfoliated graphite, $\mathrm{CuO}, \mathrm{ZnO}, 4-N i t r o p h e n o l$, photoelectrochemical degradation, photocatalysis.

\section{FULL TEXT}


(C) 2019 The Authors. Published by ESG (www.electrochemsci.org). This article is an open access article distributed under the terms and conditions of the Creative Commons Attribution license (http://creativecommons.org/licenses/by/4.0/). 